\title{
Conditioned acceleration and free-operant wheel-turn avoidance following septal lesions in rats*
}

\author{
ANTHONY DICKINSON and R. G. M. MORRIS $\dagger$ \\ Laboratory of Experimental Psychology, University of Sussex \\ Brighton, England, BN1 9QG
}

\begin{abstract}
Free-operant wheel-turn avoidance performance of rats with septal lesions and controls was studied in detail. Septal damage decreased the overall response and shock rates and the vigor of the "burst" pattern of responding. Both groups of rats were then given a series of Pavlovian conditioning trials in a separate apparatus. During these sessions, a 5-sec tone was followed by an unavoidable shock on half of the trials and by a 5-sec light stimulus on the remaining trials. Subsequently these stimuli were presented while the animals responded on the free-operant wheel-turn avoidance schedule. The magnitude of the response-rate acceleration produced by the tone in both groups was unaffected by the lesion. The light did not develop rate-inhibiting properties in either group of animals. These results provide no evidence that septal damage attenuates Pavlovian fear conditioning.
\end{abstract}

Septal damage has marked effects on behavior controlled by aversive stimuli. Two of the most notable are the increased resistance of appetitive responses to suppression by both response-contingent and noncontingent shocks (e.g., Dickinson, 1974; Harvey, Lints, Jacobson, \& Hunt, 1965; Schwartzbaum \& Speith, 1964) and the enhanced performance in a two-way active-avoidance paradigm (e.g., King, 1958; Krieckhaus, Simmons, Thomas, \& Kenyon, 1964; Schwartzbaum, Green, Beatty, \& Thompson, 1967).

Two basic types of explanation have been proposed for these dysfunctions. Certain authors (e.g., Kenyon \& Kriekhaus, 1965; Lubar \& Numan, 1973) have suggested that septal lesions attenuate conditioned fear. Their view is supported by several demonstrations that decreases in shock intensity for normal animals produce response changes which parallel those of septal damage in both response suppression (e.g., Annau \& Kamin, 1961; Azrin, 1960) and avoidance situations (e.g., Moyer \& Korn, 1964; Theios, Lynch, \& Lowe, 1966). The alternative hypothesis argues that the septal dysfunction reflects a general inability to inhibit somatic response rather than a change in the motivational or emotional state of the animal (e.g., McCleary, 1966). The potential role of response inhibition in punishment and conditioned suppression is obvious, and recent evidence suggests that response inhibition may also be involved in two-way avoidance (Freedman, Hennessy, \& Groner, 1974). Attenuation of the suppressive effects of shock in two-way avoidance could underlie the facilitation of performance following septal damage (Garber \& Simmons, 1968).

One purpose of the following experiment was to

*This work was aided by a grant from the U.K. Medical Research Council. Computing facilities at the University of Sussex were made available by a grant from the U.K. Science Research Council. The authors would like to thank Colin Atherton for photographic assistance.

+ Now at the University of Durham. investigate whether septal lesions interfere with fear conditioning independently of any change in response inhibition. A conditioned acceleration procedure was used (Rescorla \& Lolordo, 1965) in which response rate on a free-operant (Sidman) avoidance schedule typically increases during the presentation of a CS paired with an unavoidable shock in a previous Pavlovian stage. The degree of the acceleration appears to be monotonically related to the US magnitude (Martin \& Riess, 1969; Riess \& Farrar, 1973; Riess \& Martin, 1969) given that the US is not very intense relative to the shock scheduled by the avoidance procedure (Scobie, 1972). In addition to measuring the excitatory effects of conditioned fear, another CS was presented in a "conditioned inhibition" procedure during the Pavlovian stage to see whether septal damage would affect the development of conditioned inhibition of fear (Rescorla \& LoLordo, 1965; Weisman \& Litner, 1969).

A second purpose of the experiment was to make a detailed study of free-operant avoidance behavior following septal damage. Septal lesions in rats have been found to decrease both response (Morgan \& Mitchell, 1969; Sodetz, 1970, 1972) and shock rates (Morgan \& Mitchell, 1969; Sodetz, 1970; Duncan \& Duncan, 1971) on leverpress free-operant avoidance. This increased efficiency presents difficulties for both hypotheses under consideration. As a decrement in shock intensity reduces the response output and increases the shock rate for normal animals (Powell, 1970; Riess, 1970; Riess \& Ferrar, 1972), it is difficult to reconcile these effects with fear reduction. An explanation in terms of response disinhibition fares no better as the increased efficiency of the brain-damaged rats appears to be at least partially due to the fact that they can space their responses more appropriately (Morgan \& Mitchell, 1969; Sodetz, 1970, 1972). More detailed study of the patterns of responding on free-operant avoidance tasks following septal lesions seems necessary. 


\section{METHOD}

\section{Subjects}

The subjects were 20 male hooded Lister rats with a mean weight of $410 \mathrm{~g}$ (range: $330-473 \mathrm{~g}$ ) at the start of training.

\section{Apparatus}

Two wheel-turn and two Pavlovian conditioning chambers $(25 \times 25 \times 25 \mathrm{~cm})$ housed in individual sound-attenuating cubicles were used. Three walls and the ceiling of the wheel-turn chambers were constructed of aluminum. The remaining wall was made of white transparent acrylic plastic and hinged to allow access to the chamber. This door could be transilluminated by a $250-\mathrm{V}, 25-\mathrm{W}$ lamp. A $15-0 \mathrm{hm}$ speaker was mounted in the ceiling as another stimulus source. The whel-turn manipulandum was suspended horizontally in one end wall and measured $8.8 \mathrm{~cm}$ in diam and $11.5 \mathrm{~cm}$ in length. It was constructed of 12 stainless steel bars, $.63 \mathrm{~cm}$ in diam, mounted in circular aluminum end plates. A ratchet arrangement permitted the rats to rotate the wheel by downward strokes of the forepaws. Small magnets were mounted on the end plates every $90 \mathrm{deg}$. Rotation of the wheel through 90 deg operated a switch and activated a heavy-duty relay mounted on the outside of the chamber to provide auditory response "feedback." The grid floor consisted of 11 stainless steel bars, $.63 \mathrm{~cm}$ in diam, arranged to lie parallel to the end walls. The wheel, side walls, and grid floor could all be charged independently. The Pavlovian conditioning chambers were of similar construction except that all the walls were of aluminum and no wheel was present. In addition, the ceiling was hinged and made of translucent plastic which could be transilluminated by a $250-\mathrm{V}, 25-\mathrm{W}$ lamp.

The excitatory stimulus (CS+) was a 1,000-cps tone which raised the total sound level in the vicinity of the wheel from approximately $65 \mathrm{~dB}$ to $75-80 \mathrm{~dB}$ (re: $.0002 \mathrm{dynes} / \mathrm{cm}^{2}$ ). Illumination of the lamps served as the inhibitory stimulus (CS-). Electric shocks could be presented in both types of chamber from Grason-Stadler shock generators (E1064GS). A response was defined as the rotation of the wheel through $90 \mathrm{deg}$. The control of events and the monitoring of responses were carried out on line by an Elliott 4130 computer utilizing the experimental control language (ECL) and systems developed in this Laboratory (Francis \& Sutherland, 1969).

\section{Surgery}

Before surgery, the rats were randomly divided into a septal-lesion $(N=10)$ and control group $(N=10)$. During the operation, the rats were anesthetized by pentobarbital $(40 \mathrm{mg} / \mathrm{kg})$ with ether supplement. Bilateral lesions were produced in members of the lesion group by passing a 2-mA anodal current for $20 \mathrm{sec}$ through the $.5-\mathrm{mm}$ uninsulated tip of a stainless steel needle. The electrode was placed stereotaxically with the skull horizontal $1.0 \mathrm{~mm}$ anterior to bregma, $3.0 \mathrm{~mm}$ lateral to the midline, and $5.5 \mathrm{~mm}$ below the surface of the brain at an angle of $25 \mathrm{deg}$ toward the midline. Control animals were subjected to an identical surgical procedure except that the electrode was not lowered into the brain.

At the end of the experiment, the brain-damaged subjects were given an overdose of pentobarbital and were intracardially perfused with $.9 \%$ saline followed by Susa solution. The brains were extracted from the skull and embedded in paraffin. Sections were cut at 10 microns, and every 10 th section was mounted and stained with cresyl violet.

\section{Procedure}

All animals received experience of leverpress acquisition and extinction with food reinforcement immediately following surgery for the purposes of another study. Avoidance training was started 2 to 3 months following the operation. The experiment was divided into three stages.
Table 1

Performance on Session 4 of Avoidance Training

\begin{tabular}{lrcl} 
& Septal & Control & \multicolumn{1}{c}{ t Test } \\
\hline Response Rate* & 27.1 & 47.2 & $\mathrm{p}<.025$ \\
Postresponset & 7.8 & 12.3 & $\mathrm{p}<.05$ \\
Postshockt & 4.0 & 13.9 & $.05<\mathrm{p}<.10$ \\
\hline
\end{tabular}

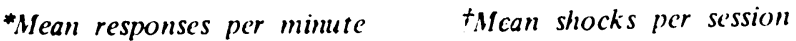

Avoidance Training. Initially the rats were trained to respond on a free-operant avoidance schedule with a shock-shock interval of $5 \mathrm{sec}$, a response-shock interval of $20 \mathrm{sec}$, and a shock of $.6 \mathrm{~mA}$ intensity and $.3 \mathrm{sec}$ duration. Four daily $5($ )-min sessions were administered under these conditions. During the fifth session. tone and light pretest trials were scheduled intermittently according to a Gellermann sequence. Fach trial consisted of seven successive 5-sec periods, and the intervals between trials were 35,65 , or $90 \mathrm{sec}$. The first trials were not presented until a 10 -min "warm-up" period had elapsed from the start of the session. The light or tone stimulus was presented during the fourth 5 -sec period of a trial, and the number of response and shocks occurring during each of the seven periods were recorded separately. The session continued until 12 trials of each stimulus, totally free of shocks, had occurred. In the event of no shocks occurring during any trials. the session lasted for $50 \mathrm{~min}$ inclusive of the 10-min "warm-up" period. The free-operant schedule was in effect throughout this and all the subsequent test sessions.

Pavlovian Conditioning. On the next session, 30 excitatory and 30 inhibitory conditioning trials were administered according to a Gellermann sequence in the Pavlovian chambers. On an excitatory trial, the tone (CS+) was presented for 5 sec and terminated by a .3-sec . 8 -mA shock. On inhibitory trials, the tone was presented for $5 \mathrm{sec}$ and immediately followed by the light stimulus (CS-) for a further $5 \mathrm{sec}$. The inhibitory trials ended with a 180-sec period free of all stimuli and shocks. The intertrial interval was variable with a mean of $60 \mathrm{sec}$ (range: 2-24() sec). Six conditioning sessions were administered to each animal.

Transfer Testing. The rats were given one recovery session on the avoidance schedule free from any stimulus presentations followed by four transfer test sessions. The procedure used in these tests was identical to that employed during the stimulus pretest session.

\section{Data Analysis}

All probabilities and percentages were subjected to the transformation $X^{\prime}=2$. arcsin $\sqrt{(X)}$ before statistical analysis (Winer, 1970). Where an ANOVA was performed with unequal Ns, the unweighted means solution was employed (Winer, 1970). All individual comparisons were two-tailed.

\section{RESULTS}

\section{Avoidance Performance}

In order to assess whether the lesion affected responding on the avoidance schedule, performance on the fourth training session excluding the "warm-up" period was subjected to a detailed analysis. Table 1 shows that the lesion group emitted a lower response rate and received fewer shocks. The shocks were classified on the basis of whether the immediately preceding event was a response or another shock. The lesion reduced the number of both types of shock received, although the reduction in the number of 


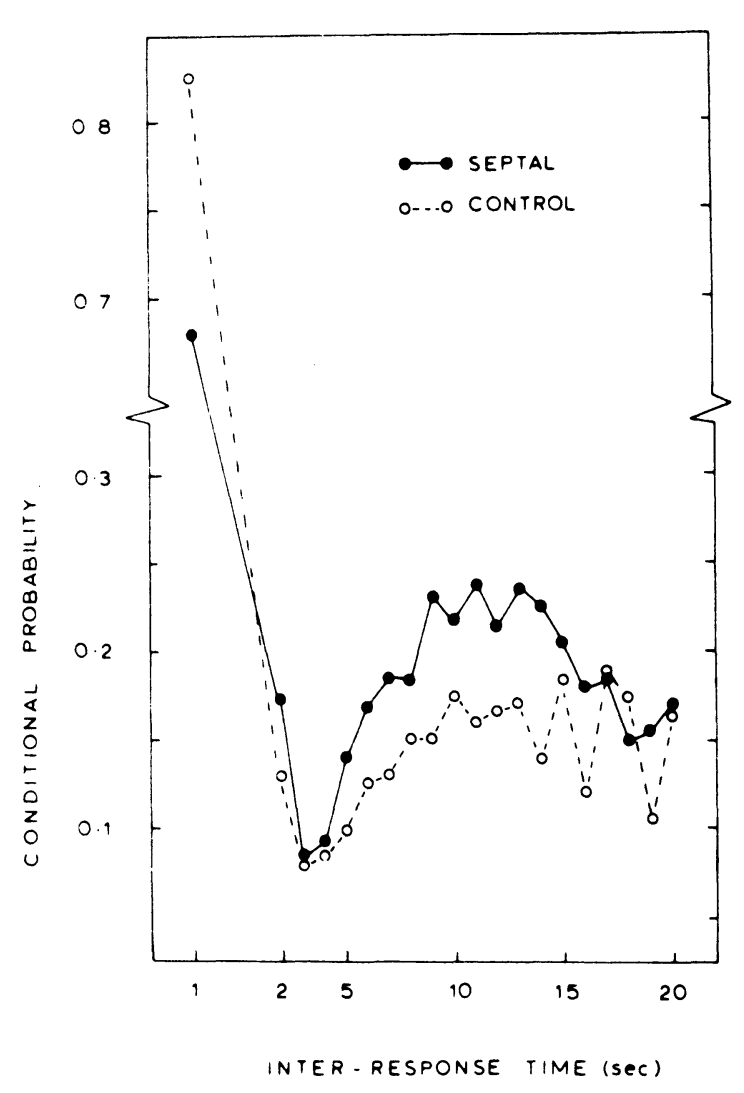

Figure 1. Conditional probability (IRT/opportunity) of interresponse times during Session 4 of avoidance training.

shocks following a shock was only marginally significant. The conditional probabilities of interresponse times
Table 2

Analysis of Response "Bursts" on Session 4 of Avoidance Training

\begin{tabular}{lccccc}
\hline & \multicolumn{2}{c}{ Septal } & & \multicolumn{2}{c}{ Control } \\
\cline { 2 - 3 } \cline { 5 - 6 } & $\begin{array}{c}\text { Post- } \\
\text { response }\end{array}$ & $\begin{array}{c}\text { Post- } \\
\text { shock }\end{array}$ & & $\begin{array}{c}\text { Post- } \\
\text { response }\end{array}$ & $\begin{array}{c}\text { Post- } \\
\text { shock }\end{array}$ \\
\hline Response Rate* & 148.9 & 203.3 & & 200.8 & 237.9 \\
Response Number & 2.91 & 7.34 & & 8.24 & 14.40 \\
Burst Duration (Sec) & 1.05 & 2.06 & & 2.22 & 3.49 \\
\hline * & 1.02 & & & &
\end{tabular}

*Mean responses per minute

(IRTs) of different durations (IRT/opportunity) are illustrated in Figure 1. Both groups showed a high probability of emitting IRTs of less than $1 \mathrm{sec}$, this probability being lower for the brain-damaged than for control animals $(\mathrm{t}=2.67, \mathrm{df}=1 / 18, \mathrm{p}<.01)$. Animals in both groups also showed some evidence of spacing their responding in that with increasing IRTs the probability initially dropped to a minimum at about $3 \mathrm{sec}$ and then rose to a maximum at about $10 \mathrm{sec}$. The lesion group generally had a higher probability of emitting long IRTs than controls.

The high probability of IRTs of less than $1 \mathrm{sec}$ was due to the fact that the rats tended to respond in "bursts." In order to analyze this pattern in more detail, a "burst" was defined as any group of successive responses with IRTs of less than $1 \mathrm{sec}$. The mean duration of the "bursts" and the mean number of responses and the mean response rate within the "bursts" were calculated separately for "bursts" of two types: "bursts" begun at least $1 \mathrm{sec}$ after a preceding response (postresponse "bursts") and "bursts" begun at any time after a shock (postshock "bursts"). The result of this analysis is shown in Table 2. On all three measures, "bursting" following a shock was more
Figure 2. The relative frequency of "bursts" of different lengths during Session 4 of avoidance training.

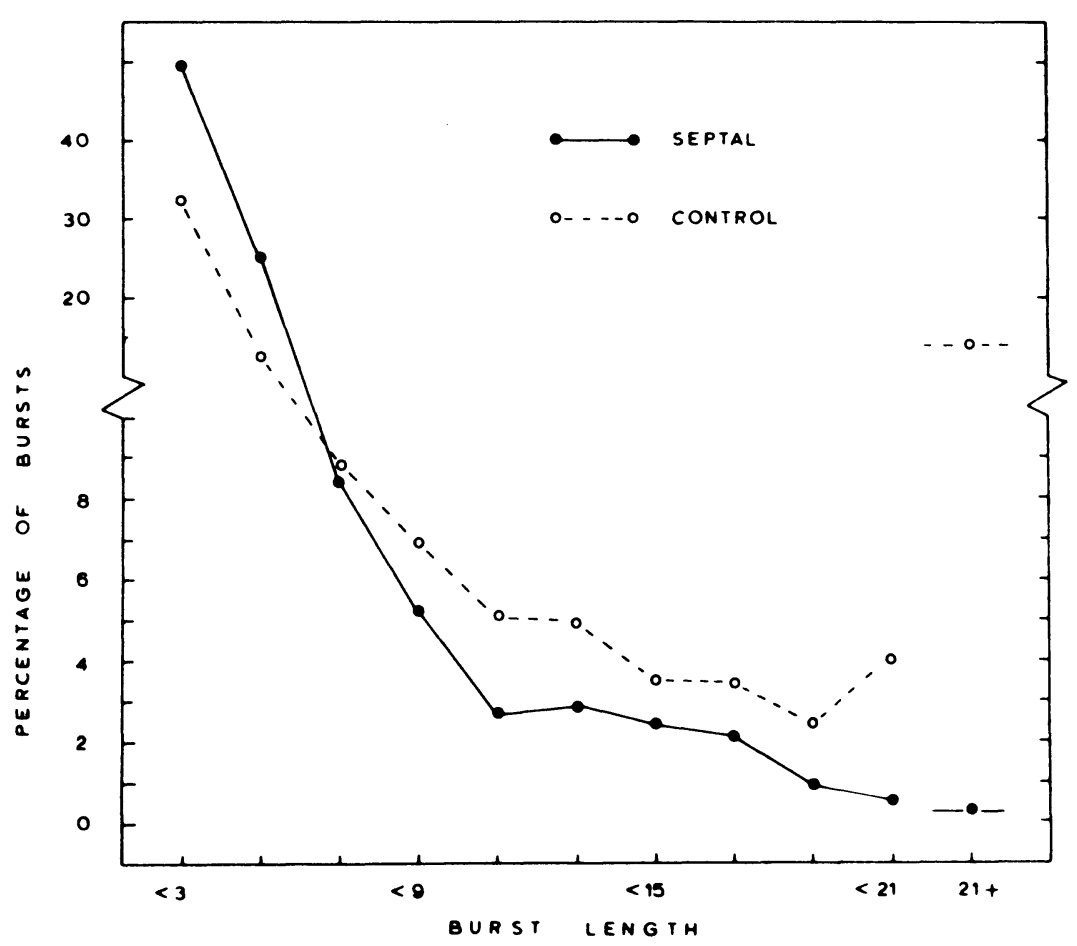




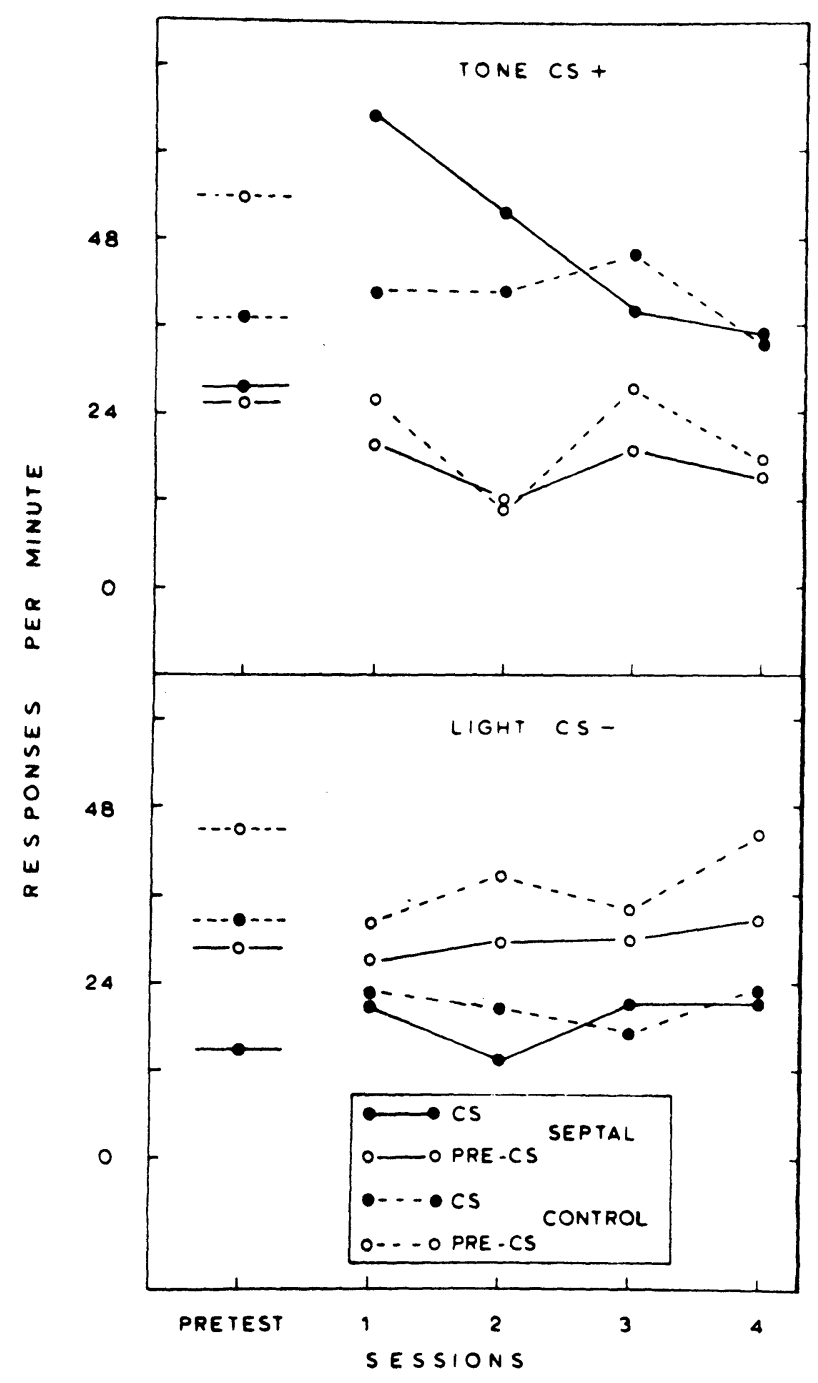

Figure 3. Mean response rates during the 5-sec pre-CS period and during $C S$ presentation on the pretest session and all four test sessions. The top panel illustrates the rates for tone trials (CS+) and the bottom panel for light trials (CS-).

sustained than following a response (rate: $F=37.54$, number: $F=14.22$, and time: $F=13.42$, $\mathrm{df}=1 / 18$, $\mathrm{p}<.01)$. The lesion group showed less sustained and vigorous "bursting" than controls (rate: $F=7.59$, number: $F=6.09$, and time: $F=6.94, \mathrm{df}=1 / 18$, $\mathrm{p}<.025)$. However, the effect of the lesion did not interact with that of the preceding type of event (shock vs response) (rate: $\mathrm{F}=1.34, \mathrm{df}=1 / 18, \mathrm{p}>.25$, number: $F<1$, time: $F<1)$. The overall effect of the lesion on "burst" vigor was due to a general shift in the distribution of the number of responses in a "burst" toward lower values. Figure 2 illustrates the percentage of bursts of different lengths. There was a significant interaction between the lesion and the number of responses in a "burst" for "burst" lengths between 2 and
20 responses $(F=3.08, d f=9 / 162, p<.01)$. Also, the percentage of "bursts" longer than 20 responses was higher for the control than for the lesion group $(U=3$, $\mathrm{p}<.01)$.

\section{Transfer Performance}

Only trials on which no shock was presented during the seven 5 -sec periods could be used to assess the effects of the stimuli on avoidance responding. Consequently, in order to accumulate sufficient of these shock-free trials and to minimize the effects of fortuitous pairings of the stimuli with shocks delivered by the avoidance schedule, only animals with a shock rate lower than 30 shocks per hour, excluding the "warm-up," throughout all four test sessions were included in the analysis. This selection decreased the number of subjects in the lesion and control groups to eight and six, respectively. Even so, the remaining experimental subjects had a lower shock rate than the controls during the test sessions $(t$ test, $p<.01)$. The mean shock rate across all four test sessions was 9.2 shocks per hour for the lesion group and 22.1 shocks per hour for the control group.

Figure 3 shows the response rate in the 5 -sec stimulus period (CS) and the preceding 5-sec period (pre-CS) for tone (top panel) and light trials (bottom panel) during the pretest and all transfer test sessions. Although the control animals appeared to respond faster than the lesion group on the tone pretest trials and appeared to show some unconditioned suppression to the tone, these differences were not significiant. The effect of the lesion $(F=1.22, \mathrm{df}=1 / 12, \mathrm{p}>.25)$ and the tone $(\mathrm{F}=1.64$, $\mathrm{df}=1 / 12, \mathrm{p}>.10)$ and the Lesion by Tone interaction $(\mathrm{F}=2.77, \mathrm{df}=1 / 12, \mathrm{p}>.10)$ were all insignificant. Following conditioning presentation of the tone produced response acceleration which was sustained across all four test sessions. A comparison of the response rates on the pretest sessions to those on the first transfer test session revealed a significant Tone by Session interaction $(\mathrm{F}=13.51, \mathrm{df}=1 / 12, \mathrm{p}<.01)$. However, the lesion did not appear to affect the magnitude of this acceleration; the Lesion by Tone by Session interaction failed to reach significance $(F<1)$. In addition, all other effects and interactions involving the lesion were not significant. Separate analysis of performance across the four test sessions showed that the acceleration produced by the tone was sustained $(\mathrm{F}=6.51, \mathrm{df}=1 / 12, \mathrm{p}<.05)$. Although the graphic data suggest that the magnitude of the acceleration systematically declined across sessions for the lesion group, this conclusion was not supported by statistical analysis. The main effects of the lesion and sessions were insignificant, as were all the interactions between these factors and the effect of the tone. Figure 4 shows the response rates of the lesion and control groups during the seven 5 -sec periods of tone trials averaged across all 
the test sessions. The response rate profiles for brain-damaged and intact animals were very similar.

Unfortunately, the light stimulus (Figure 3, bottom panel) tended to produce unconditioned suppression in some animals. The effect though was not significant $(F=2.30, \mathrm{df}=1 / 12, \mathrm{p}>.10)$ and did not interact with the lesion. A comparison of performance on the first transfer test session and the pretest session provided no evidence that the light developed inhibitory properties. Although the main effect of the light was marginally significant $(F=4.107, \mathrm{df}=1 / 12, .10>\mathrm{p}>.05)$, this effect did not interact with sessions. The main effect of the lesion and all interactions between lesion, stimulus, and sessions were insignificant.

\section{Histology and Affective Changes}

The damage in the experimental group was typical of large septal lesions. The lateral and medial septal nuclei were totally destroyed from the genu of the corpus callosum to the crossing of the anterior commissure. The damage extended beyond the precommissural septum in the anterior direction to involve the hippocampus pars anterior and the medial parolfactory area. In addition, the diagonal band of Broca, the dorso-medial tip of the nucleus accumbens, the lateral walls of the ventricles, and the genu of the corpus callosum were invaded in all animals. In the caudal direction, the precommissural fornix and the supracommissural region of the lateral septal nucleus typically received some damage. In no case did the lesion invade structures posterior to the crossing of the anterior commissure. No obvious differences could be detected between the extent of the lesions for the two experimental subjects who failed to meet the criterion for inclusion in the transfer test and the remaining brain-damaged animals. All the lesioned animals showed the classic hyperirritability syndrome during the first few postoperative days but the hyperirritability had totally abated by the start of avoidance training.

\section{DISCUSSION}

The present study provides no evidence that septal damage attenuates the conditioned fear acquired by a neutral stimulus through Pavlovian pairings with a shock when a response acceleration measure is used. This finding seriously questions an interpretation of the reduction in the suppressive effects of aversive stimuli following septal damage in terms of an attenuation of conditioned fear. The pattern of response acceleration was essentially similar to that found in previous experiments (Rescorla \& LoLordo, 1965; Weisman \& Litner, 1969) with the acceleration initially occurring during the CS presentation and persisting into the 5 -sec interval after its offset. However, the failure to demonstrate an inhibitory effect of the light over and above its unconditioned suppressive effects is at variance with previous experiments. Weisman and Litner (1969) found strong suppressive effects in rats using a Pavlovian

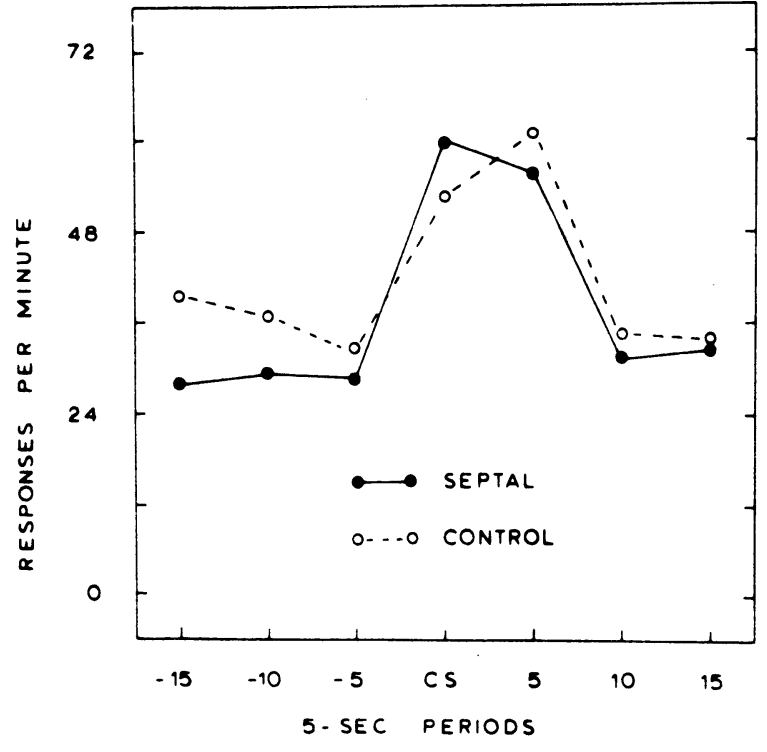

Figure 4. Mean response rates during the preCS periods, CS presentation, and post-CS periods for tone trials (CS+) averaged over all four test sessions.

"conditioned inhibition" paradigm with a comparable procedure and parameters. Although the reason for this discrepancy is not clear, it is possible that the unconditioned suppression produced by the light masked any conditioned effect.

Septal damage produces changes in wheel-turn responding on a free-operant avoidance schedule which are comparable to the effects seen when a leverpress response is used. There is a decrement in both the shock (Duncan \& Duncan, 1971; Morgan \& Mitchell, 1969; Sodetz, 1970) and response rates (Morgan \& Mitchell, 1969; Sodetz, 1970, 1972) and an increase in the probability of emission for long IRTs (Morgan \& Mitcehll, 1969; Sodetz, 1970, 1972). In addition there is a reduction in the amount of "bursting" as indexed by the reduced probability of short IRTs. The present results show that this reduction is general, covering the "burst" duration and the response rate with a "burst."

At present there seems to be no compelling explanation of the changes in avoidance performance following the lesion. The improvement has been related to a change in the response pattern elicited by the shock (Duncan \& Duncan, 1971; Middaugh, Hurwitz, Knapp, \& Huchinson, 1972). Middaugh et al. (1972) reported that septal damage decreased the number of responses occurring immediately following the shock. However, the present results show that this reduction is not peculiar to postshock "bursting." In fact, the shock produced comparable increments in the "burst" strength for the lesion and control groups. It should be noted, though, that the reduction in overall response output might well be limited to certain classes of responses for Kelsey and Grossman (1971) found a higher response rate on a free-operant avoidance schedule in a shuttlebox following septal damage. Sodetz (1972) has suggested that the change in avoidance performance is due to a 
lesion-induced deficit in the conditioning of aversive properties to interoceptive stimuli. This could well account for the general reduction in "burst" strength. However, the present study demonstrates that any such deficit must be peculiar to interoceptive stimuli, for when a conditioned aversive external stimulus is superimposed, equivalent increments in responding are found for experimental and control animals.

\section{REFERENCES}

Annau, Z., \& Kamin, L. J. The conditioned emotional response as a function of intensity of the US. Journal of Comparative and Physiological Psychology, 1961, 54, 428-432.

Azrin, N. H. Effects of punishment intensity during variable-interval reinforcement. Journal of the Experimental Analysis of Behavior, 1960, 3, 123-142.

Dickinson, A. Suppressive and enhancing effects of footshock on food-reinforced operant responding following septal lesions in rats. Journal of Comparative and Physiological Psychology, 1974 , in press.

Duncan, P. M., \& Duncan, N. C. Free-operant and T-maze avoidance performance by septal and hippocampal-damaged rats. Physiology and Behavior, 1971, 7, 687-693.

Francis, J. G. F., \& Sutherland, N. S. A system for controlling animal experiments on-line. In N. Moray (Ed.), On-line computing for psychology. Unpublished document, Department of Psychology, University of Sheffield, England, 1969. Pp. 43-56.

Freedman, P. E., Hennessy, J. W., \& Groner, D. Effects of varying active/passive shock levels in shuttlebox avoidance in rats. Journal of Comparative and Physiological Psychology, $1974,86,79-84$.

Garber, E. E., \& Simmons, H. J. Facilitation of two-way avoidance performance by septal lesions in rats. Journal of Comparative and Physiological Psychology, 1968, 66, 559-562.

Harvey, J. A., Lints, C. E., Jacobson, L. E., \& Hunt, H. F. Effects of lesions in the septal area on conditioned fear and discriminated instrumental punishment in the albino rat. Journal of Comparative and Physiological Psychology, 1965, 59, 37-48.

Kelsey, J. E., \& Grossman, S. P. Nonperseverative disruption of bebavioral inhibition following septal lesions in rats. Journal of Comparative and Physiological Psychology, 1971, 75, 302-311.

Kenyon, J., \& Krieckhaus, E. E. Decrements in one-way avoidance learning following septal lesions in rats. Psychonimic Science, 1965, 3, 113-114.

King, F. A. Effects of septal and amygdaloid lesions on emotional behavior and conditioned avoidance responses in the rat. Journal of Nervous and Mental Disease, 1958, 126, 57-63.

Krieckhaus, E. E., Simmons, H. J., Thomas, G. J., \& Kenyon, J. Septal lesions enhance shock avoidance in the rat. Experimental Neurology, 1964, 9, 107-113.

Lubar, J. F., \& Numan, R. Behavioral and physiological studies of septal function and related medial cortical structures. Behavioral Biology, 1973, 8, 1-25.

Martin, L. K., \& Riess, D. Effects of US intensity during previous discrete delay conditioning on conditioned acceleration during avoidance extinction. Journal of Comparative and Physiological Psychology, 1969, 69, 196-200.
McCleary, R. A. Response-modulating functions of the limbic system: Initiation and suppression. In E. Stellar and J. M. Sprague (Eds.), Progress in physiological psychology. Vol. 1. New York: Academic Press, 1966. Pp. 209-272.

Middaugh, L. D., Hurwitz, H. M. B., Knapp, T. M., \& Huchinson, $W$. The effect of septal lesions in rats on performance of a free-operant avoidance task. Physiology and Behavior, 1972, 9, 59-62.

Morgan, J. M., \& Mitchell, J. C. Septal lesions enhance delay of responding on a free-operant avoidance schedule. Psychonomic Science, 1969, 16,10-11.

Moyer, K. E., \& Korn, J. H. Effect of UCS intensity on the acquisition and extinction of an avoidance response. Journal of Experimental Psychology, 1964,67, 352-359.

Powell, $R$. W. The effect of shock intensity upon responding under a multiple-avoidance schedule. Journal of the Experimental Analysis of Behavior, 1970, 14, 321-329.

Rescorla, R. A., \& LoLordo, V. M. Inhibition of avoidance behavior. Journal of Comparative and Physiological Psychology, 1965, 59, 406-412.

Riess, D. Sidman avoidance in rats as a function of shock intensity and duration. Journal of Comparative and Physiological Psychology, 1970, 73, 481-485.

Riess, D., \& Farrar, C. H. Shock intensity, shock duration Sidman avoidance acquisition, and the "all or nothing" principle in rats. Journal of Comparative and $\mathrm{Physiological}$ Psychology, 1972, 81, 347-355.

Riess, D., \& Farrar, C. H. US duration, conditioned acceleration, multiple $C R$ measurement, and Pavlovian $R-R$ laws in rats. Journal of Comparative and Physiological Psychology, 1973, 82, 144-151.

Riess, D., \& Martin, L. K. Effects of UCS intensity during continuing coterminus delay conditioning on conditioned acceleration during maintained avoidance. Psychonomic Science, 1969, 16, 251-252.

Schwartzbaum, J. S., \& Spieth, T. M. Analysis of the response inhibition concept of septal function in passive avoidance behavior. Psychonomic Science, 1964, 1, 145-146.

Schwartzbaum, J. S., Green, R. H., Beatty, W. W., \& Thompson, J. B. Acquisition of avoidance behavior following septal lesions in the rat. Journal of Comparative and Physiological Psychology, 1967, 63, 95-104.

Scobie, S. R. Interaction of an aversive Pavlovian conditional stimulus with aversively and appetitively motivated operants in rats. Journal of Comparative and Physiological Psychology, $1972,79,171-188$

Sodetz, F. J. Septal ablations and free-operant avoidance behavior in the rat. Physiology and Behavior, 1970, 5 , 773-777.

Sodetz, F. J. Sidman avoidance performance and response suppression in rats with septal lesions. Journal of Comparative and Physiological Psychology, 1972, 79, 142-150.

Theios, J., Lynch, A. D., \& Lowe, W. Differential effects of shock intensity on one-way and shuttle avoidance conditioning. Journal of Experimental Psychology, 1966, 72 , 294-299.

Weisman, R. G., \& Litner, J. S. The course of Pavlovian excitation and inhibition of fear in rats. Journal of Comparative and Physiological Psychology, 1969, 69, 667-672.

Winer, B. J. Statistical principles in experimental design. New York: McGraw-Hill, 1962.

(Received for publication June 18, 1974; revision received August 27, 1974.) 